\title{
The effects of dietary ligands on zinc uptake at the porcine intestinal brush-border membrane
}

\author{
BY A. J. TURNBULL ${ }^{1}$, P. BLAKEBOROUGH ${ }^{2 *}$ AND R. P. H. THOMPSON ${ }^{1} \dagger$ \\ ${ }^{1}$ Gastrointestinal Laboratory, Rayne Institute, St Thomas' Hospital, London, SE1 7EH \\ ${ }^{2}$ AFRC Institute of Food Research, Reading Laboratory, Shinfield, Reading, RG2 $9 A T$
}

Received 12 December 1989 - Accepted 13 June 1990)

Intestinal brush-border-membrane vesicles were prepared from the porcine small bowel by magnesium precipitation and differential centrifugation, and were functionally intact. The influence of dietary ligands on ${ }^{65} \mathrm{Zn}$ uptake was determined using a ${ }^{65} \mathrm{Zn}$ concentration of $5 \mu \mathrm{M}$, an incubation time of 1 min and a reaction temperature of $27^{\circ}$, with a rapid filtration technique. At this low $\mathrm{Zn}$ concentration the addition of an excess of folate, histidine or glucose had no effect on $\mathrm{Zn}$ uptake. Addition of picolinate, citrate and phytate to the incubation medium significantly reduced $\mathrm{Zn}$ uptake at all concentrations of ligand examined. Any inhibitory effects of folic acid in vivo may thus be due to a mucosal rather than lumen interaction. Those ligands inhibiting absorption may have done so through the formation of $\mathrm{Zn}$-ligand complexes, which are either insoluble, or which reduce the binding of $\mathrm{Zn}$ to its mucosal receptor. This in vitro model of $\mathrm{Zn}$ absorption is useful for comparing the effects of potential $\mathrm{Zn}$-binding ligands in the diet.

Zinc absorption: Ligands: Pig

Several studies have shown that, even in the otherwise well-nourished, the dietary intake of Zn may be marginal (Solomons, 1982; Black et al. 1986; Southon et al. 1988). This precarious $\mathrm{Zn}$ balance may be further compromised by conditions of increased demand, such as pregnancy, growth and lactation. Under such conditions, the inclusion in the diet of nutrients that chelate $\mathrm{Zn}$ may significantly affect $\mathrm{Zn}$ status.

Several models have been used for the study of $\mathrm{Zn}-$ nutrient interactions. Brush-bordermembrane vesicles are convenient for examining the first phase of nutrient absorption in isolation, and studies on intestinal glucose and calcium transport have shown that the results obtained with brush-border-membrane vesicles are qualitatively comparable to those with intact epithelial preparations (Murer \& Kinne, 1980). They have been used previously to study the absorption of several divalent cations including $\mathrm{Zn}$ (Menard \& Cousins, 1983a; Blakeborough \& Salter, 1987), the uptake of which is biphasic. The first phase, which is saturable, probably represents carrier-mediated, facilitated diffusion, and this predominates when the $\mathrm{Zn}$ concentration is below $10 \mu \mathrm{M}$. The second, non-saturable phase results from non-specific binding of $\mathrm{Zn}$ to the membrane (Blakeborough \& Salter, 1987).

Both citrate (Hurley et al. 1979) and picolinate (Evans \& Johnson, 1980) have been proposed to enhance the absorption of $\mathrm{Zn}$ from milk, but the importance of either in vivo is controversial (Cousins \& Smith, 1980; Hurley \& Lonnerdal, 1981; May et al. 1982), and the precise site at which these ligands act is uncertain. In man, an inhibitory effect of folate on $\mathrm{Zn}$ absorption has been suggested (Milne et al. 1984; Simmer et al. 1987), but not confirmed in all studies (Keating et al. 1987). Conversely, glucose (Steinhardt \& Adibi,

\footnotetext{
* Present address: Medical Writing Services, Glaxo Group Research Ltd, Greenford, Middlesex.

$\dagger$ For reprints.
} 
1984) and histidine (Scholmerich et al. 1987) enhance Zn absorption in man, although their site and mechanism of action are also unclear. In the present study these ligands have been re-examined specifically for their effect at the intestinal brush-border membrane.

\section{MATERIALS AND METHODS}

\section{Materials}

Carrier-free ${ }^{65} \mathrm{Zn}(0.52 \mu \mathrm{Ci} / \mathrm{ml}, 0.38 \mu \mathrm{g} \mathrm{Zn} / \mathrm{ml})$ was purchased from Amersham International plc, Amersham, Bucks. Polycose (glucose polymer) was obtained from Abbott Laboratories, Queensborough, Kent. 'Analar' grade Zn sulphate was obtained from BDH Ltd, Poole, Dorset, and all other chemicals, including phytic acid (dodecasodium inositol hexaphosphoric acid), folic acid (pteroylglutamic acid) and picolinic acid (2-pyridine carboxylic acid), were obtained from Sigma Chemical Co., Poole, Dorset. All glassware was acid washed and rinsed twice in de-ionized water. Solutions were made up in distilled de-ionized water.

\section{Preparation of intestinal brush-border-membrane vesicles}

Pigs ( $28 \mathrm{~d}$ of age) given a normal-Zn diet were obtained from the piggery of the AFRC Institute of Food Research, Shinfield, Berkshire. They were killed and the entire small intestine was immediately excised and rinsed with ice-cold normal saline $(9 \mathrm{~g}$ sodium chloride $/ 1$ ) before storing at $-20^{\circ}$. Vesicles were prepared by the method of Booth \& Kenny (1974). The defrosted intestine was cut into small pieces and suspended in $300 \mathrm{~mm}-$ mannitol, $12 \mathrm{~mm}$-Tris at $\mathrm{pH} 7 \cdot 1$. Enterocytes were isolated by vortex mixing and filtration through a $1 \mathrm{~mm}$ pore size Buchner funnel. The filtrate was homogenized in a Waring-type blender and diluted 1:6 with water. Brush-border-membrane vesicles were isolated by the addition of magnesium chloride to a final concentration of $10 \mathrm{~mm}$ and incubation for $15 \mathrm{~min}$. This results in cross-linkage and precipitation of organelles and basolateral membranes, which were removed by centrifugation at $1500 \mathrm{~g}$ for $12 \mathrm{~min}$. The supernatant fraction was spun at $15000 \mathrm{~g}$ for $12 \mathrm{~min}$ and the resultant pellet resuspended in $50 \mathrm{~mm}$ mannitol, $2 \mathrm{~mm}$-Tris buffer, $\mathrm{pH} 7 \cdot 1$. $\mathrm{MgCl}_{2}$ was again added to $10 \mathrm{~mm}$ final concentration and after $15 \mathrm{~min}$ incubation the preparation was centrifuged at $2200 \mathrm{~g}$ for $12 \mathrm{~min}$. The resulting supernatant fraction was centrifuged at $15000 \mathrm{~g}$ for $12 \mathrm{~min}$ to yield a final pellet of purified brush-border-membrane vesicles, which was resuspended in $50 \mathrm{~mm}$-mannitol-Tris buffer. All procedures were done at $4^{\circ}$ and portions of the final preparation stored at $-70^{\circ}$ before use.

\section{Assays of brush-border-membrane vesicles preparation}

Protein content was determined according to Bensadoun \& Weinstein (1976), using crystalline bovine serum albumin as the protein standard. The degree of purification of the preparation over the crude homogenate was estimated by determination of the enrichment of alkaline phosphatase (EC 3.1.3.1), a marker enzyme of the brush-border membrane (Murer et al. 1976).

\section{Uptake studies}

Uptake studies were performed as previously described (Blakeborough \& Salter, 1987) with slight modifications. Incubation solution ( $\mathrm{pH} \mathrm{7.5)}$ containing $5.0 \mu \mathrm{M}-\mathrm{zinc}$ sulphate, $150 \mathrm{~mm}$ sodium chloride, $20 \mathrm{~mm}$-Tris and the ligand under investigation were prepared and $0.22 \mu \mathrm{Ci}$ ${ }^{65} \mathrm{Zn} / \mathrm{ml}$ added. The ligands used were folic acid $(0 \cdot 05,0 \cdot 5,5 \cdot 0$ and $50 \cdot 0 \mu \mathrm{M})$, citric acid $(0 \cdot 1$, 0.5 and $1.0 \mathrm{~mm})$, picolinic acid $(25,250$ and $500 \mu \mathrm{M})$, phytic acid $(250$ and $500 \mu \mathrm{M})$, glucose $(5,10$ and $50 \mathrm{~mm})$, Polycose $(5$ and $10 \mathrm{~mm})$ and histidine $(5$ and $20 \mu \mathrm{M})$. Uptake was initiated by the addition of brush-border-membrane vesicles containing $50 \mu \mathrm{g}$ protein to 
$0.5 \mathrm{ml}$ of the incubation solution at $27^{\circ}$. Reactions were conducted for $1 \mathrm{~min}$ and were terminated by adding $5.0 \mathrm{ml}$ ice-cold Tris- $\mathrm{NaCl}$ buffer. The incubate immediately underwent rapid filtration through a pre-wetted cellulose nitrate membrane filter (Whatman Ltd, Maidstone, Kent) of pore size $0.45 \mu \mathrm{m}$. A further $5 \mathrm{ml}$ buffer was used to ensure transfer of the entire sample to the filter, and the latter washed twice with $5 \mathrm{ml}$ portions of buffer. ${ }^{65} \mathrm{Zn}$ uptake by the vesicles retained on the filter was estimated using an LKB 1282 gamma counter. To allow for adhesion of the isotope to the membrane, filter blanks were treated as described previously but the stop solution added simultaneously with the brushborder-membrane vesicles. Uptake was measured for each ligand using material from three preparations, and for each preparation six replicates and four blanks were performed. Mean activity of the blanks was subtracted from that of the incubated samples and uptake expressed as nmol $\mathrm{Zn} / \mathrm{mg}$ membrane protein.

\section{Statistical analysis}

For each preparation ( $n 3)$ mean $\mathrm{Zn}$ uptake over a range of ligand concentrations was calculated, and by subtracting this value from the mean value of uptake of $\mathrm{Zn}$ in the absence of ligand, the mean change in $\mathrm{Zn}$ uptake was derived for the three preparations. Its significance was estimated using a paired $t$ test (mean uptake with ligand $v$. mean uptake without). In addition, by pooling the individual standard deviations from the six replicates of each sample, a residual standard deviation (RSD) was calculated.

\section{RESULTS}

\section{Assays}

Alkaline phosphatase assay showed an enrichment in specific activity of at least ninefold in all preparations which was considered a sufficient degree of purification for use in uptake studies. Lysis of brush-border-membrane vesicles in Triton X100, at a concentration of $0.5 \mathrm{~g} / 1$ buffer, resulted in no increase in enzyme activity, indicating that the vesicles were orientated predominantly right side-out (Haase et al. 1978).

\section{Zn uptake}

Reproducibility. Uptake of $\mathrm{Zn}$ alone was examined on two separate occasions in each of seven preparations. Mean values of $\mathrm{Zn}$ uptake for the six different preparations used ranged from 5.57 to $12.48 \mathrm{nmol} / \mathrm{mg}$ protein per min. The percentage error of the assay performed on two occasions was $0 \cdot 1-5 \cdot 5$ (mean $3 \%$ ) and the within-run coefficient of variation was $5.6-29 \%$ (mean $12 \%$ ).

Effects of ligands. Generally, although the preparations differed quantitatively in the absolute amount of $\mathrm{Zn}$ taken up, qualitatively they behaved similarly when ligands were added to the incubate.

The addition of folic acid to the incubation medium did not significantly change $\mathrm{Zn}$ uptake over a range of folate concentrations from 0.05 to $50 \mu \mathrm{M}$ (Fig. 1(a)). Assuming a daily uptake of $\mathrm{Zn}$ of $15 \mathrm{mg}$ and folic acid of $400 \mu \mathrm{g}$ (US recommended daily allowances; National Research Council, 1980), all the concentrations tested were in excess of the $1: 250$ molar folate: $\mathrm{Zn}$ ratio present in the normal diet.

Citric acid $(100-1000 \mu \mathrm{M})$ markedly reduced $\mathrm{Zn}$ uptake at all concentrations studied (Fig. 1(b)). Inhibition was maximal with $1 \mathrm{~mm}$-citrate, a citrate: Zn molar ratio of $200: 1$. At this concentration the $60 \%$ reduction in mean $\mathrm{Zn}$ uptake differed significantly from the control value $(n 3, P<0.05)$.

Incubation with 250 and $500 \mu \mathrm{M}$-dodecasodium phytate which, unlike calcium phytate, is soluble at $\mathrm{pH} 7 \cdot 5$, also markedly inhibited $\mathrm{Zn}$ uptake (Fig. 1(c)). A phytate: $\mathrm{Zn}$ molar ratio 

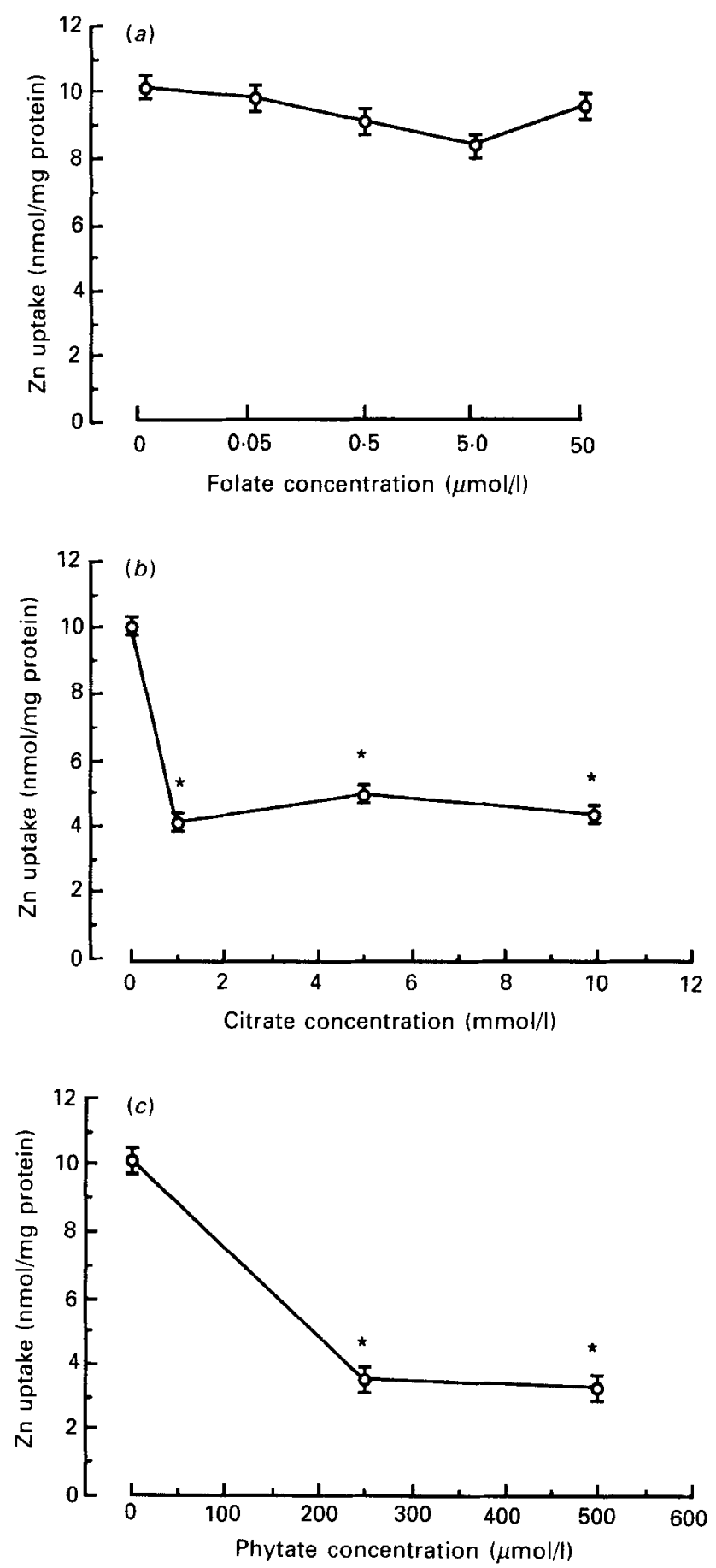

Fig. $1(a-c)$. For legend see opposite. 

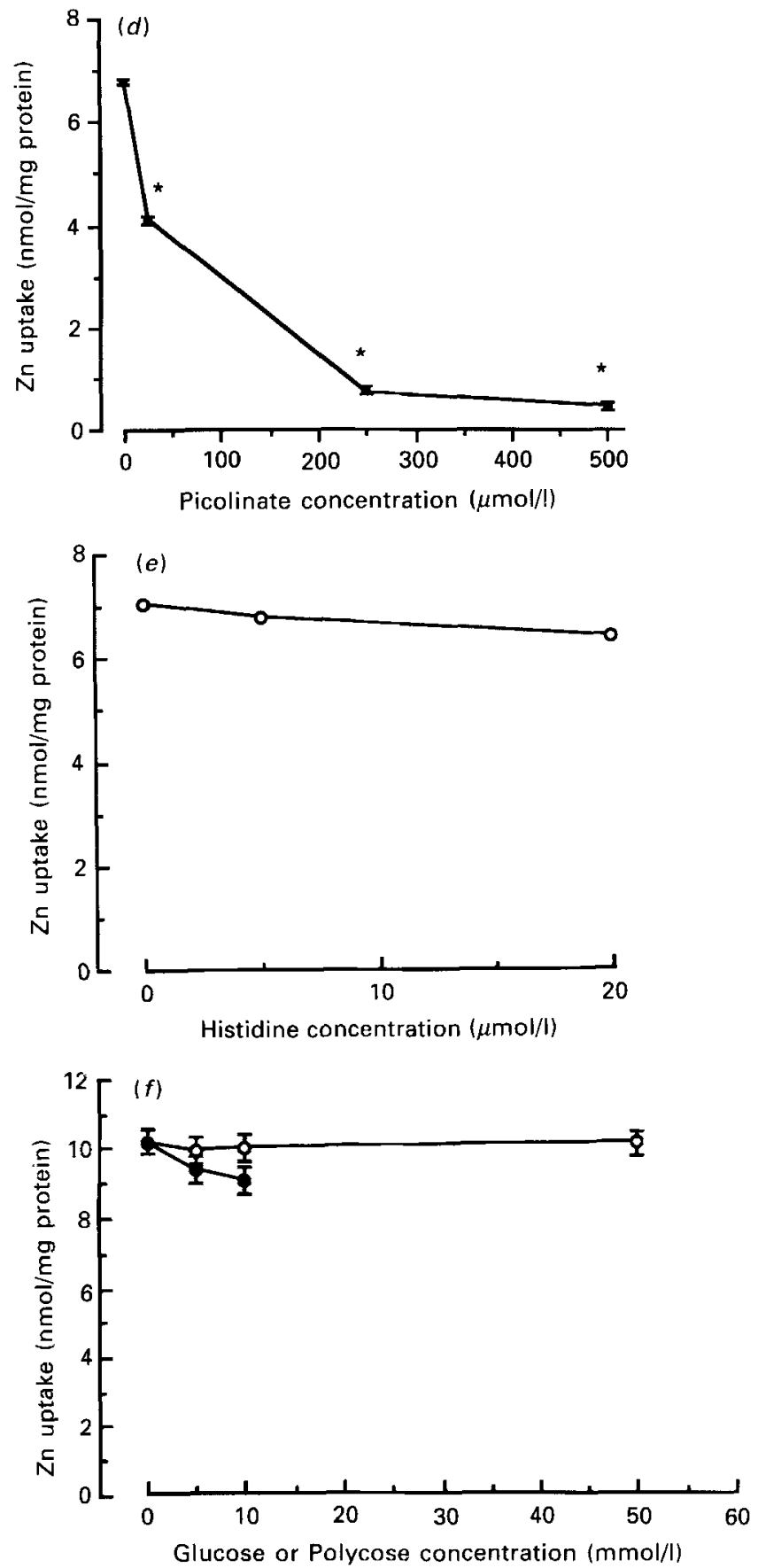

Fig. 1. The effects of increasing concentrations of nutrient ligands on zinc uptake by intestinal brush-bordermembrane vesicles. (a) Folic acid; $(b)$ citric acid; (c) phytate; $(d)$ picolinic acid; $(e)$ histidine, $(f)$ glucose $(O-O)$ or Polycose (-) Brush-border-membrane vesicles $(50 \mu \mathrm{g}$ protein) were incubated for $1 \mathrm{~min}(\mathrm{pH} 7 \cdot 5)$ in buffers containing varying ligand concentration. Results are means of eighteen experiments (six replicates of three preparations). Residual standard deviations (RSD) are shown by vertical bars (where no bars are shown, the RSD falls within the symbols). Uptake in the presence of ligand differed significantly from control values (Student's $t$ test): ${ }^{*} P<0 \cdot 05$. For details of methods, see p. 734 . 
of $50: 1$ inhibited mean uptake by $65 \%$, and doubling this ratio did not increase inhibition. The mean change in absorption at both molar ratios was statistically significant $(n 3$, $P<0.05)$.

A dose-related inhibition of uptake was found with 25-500 $\mu \mathrm{M}$-picolinic acid (Fig. $1(d)$ ). Maximal inhibition occurred at a picolinate: $Z n$ molar ratio of $100: 1$, at which point mean Zn uptake was reduced by $93 \%$.

Thus, on a mole-for-mole basis, the potency of inhibition was ranked picolinate $>$ phytate $>$ citrate.

$\mathrm{Zn}$ uptake was unaffected by histidine at either 5.0 or $20 \mu \mathrm{M}$ concentration (Fig. 1(e)). Similarly, glucose had no effect over the range 5-50 mM. Mean changes on incubation with Polycose at $5-10 \mathrm{~mm}$ were also not significant, although there was a trend to impaired uptake with increasing Polycose concentrations (Fig. 1 $(f)$ ).

\section{DISCUSSION}

The presence of dietary ligands in the intestinal lumen is a critical factor in determining the availability of ingested $\mathrm{Zn}$. Zn-ligand complexes may vary not only in their solubility and stability, but also in their site of action. In the present study the effects of nutrient ligands have been investigated entirely at the lumen-mucosa interface. Using porcine brushborder-membrane vesicles prepared by an identical technique, Blakeborough \& Salter (1987) have shown that ${ }^{65} \mathrm{Zn}$ accumulation is osmotically sensitive over a 1 min incubation period and at an extravesicular $\mathrm{Zn}$ concentration of $5 \mu \mathrm{M}$. Thus, the values we measured for $\mathrm{Zn}$ accumulation represent true uptake, rather than non-specific binding to the vesicle membrane. The pig was chosen as the source of intestinal mucosa because the anatomy and physiology of the porcine gastrointestinal tract is similar to that of man (Clarke \& Hardy, 1971; Dodds, 1982).

\section{Folate}

Not only are folates dietary constituents, but their intake is also frequently supplemented in two groups prone to $\mathrm{Zn}$ deficiency, namely pregnant women (Meadows et al. 1981) and patients with sickle cell anaemia (Prasad, 1984). In the present study no interaction in vitro between folate and $\mathrm{Zn}$ was detected at $\mathrm{pH} 7 \cdot 5$, even when folate was present in amounts equivalent to those administered therapeutically. Folates readily form complexes with trace metals, but these tend to be insoluble only at low pH (Albert, 1953). The effect of folate on $\mathrm{Zn}$ absorption in vivo is controversial. Folate-feeding studies in man (Milne et al. 1984) and intestinal perfusion studies in the rat (McMaster et al. 1985; Ghishan et al. 1986) suggest that folate in the intestinal lumen impairs $\mathrm{Zn}$ absorption by the formation of insoluble folate- $\mathrm{Zn}$ complexes, although in the feeding studies, overall $\mathrm{Zn}$ balance was unchanged. Conversely, when pregnant rats on both low and adequate $\mathrm{Zn}$ diets were given an excess of folate no change in tissue $\mathrm{Zn}$ levels was found in the dams or pups (Fuller et al. 1988), while indices of $\mathrm{Zn}$ status were normal in children on high-dose folate therapy (Krebs et al. 1988). The present findings do not preclude an adverse effect of folate on $\mathrm{Zn}$ absorption, but indicate that its site may be mucosal rather than luminal. Support for this hypothesis comes from two studies using the oral $\mathrm{Zn}$ tolerance test. Simmer et al. (1987) found reduced $\mathrm{Zn}$ absorption in patients given folate up to $24 \mathrm{~h}$ previously, whereas simultaneous administration of folate with the $\mathrm{Zn}$ had no effect (Keating et al. 1987).

\section{Citrate and picolinate}

In demonstrating a potent inhibitory effect on $\mathrm{Zn}$ absorption of these organic acids, the results largely confirm the findings of Menard \& Cousins (1983b). They noted that both ligands reduced $\mathrm{Zn}$ uptake by rat brush-border-membrane vesicles but, in contrast to the 
present study, they found citrate more potent in this respect. This disparity may either represent a species difference, or reflect the higher $\mathrm{Zn}(200 \mu \mathrm{M})$ and lower citrate $(380 \mu \mathrm{M})$ concentrations used by Menard \& Cousins (1983 b). At this level of $\mathrm{Zn}$ the contribution to uptake by non-specific binding may have been substantial. The conditions of the present study match more closely those of mature human milk, which contains $\mathrm{Zn}$ at approximately $6 \mu \mathrm{M}$ (Solomons, 1982) and citrate at 2-6 mM (Duncan \& Hurley, 1978). Using everted gut sacs, Seal \& Heaton (1983) found citrate reduced Zn uptake, but 2-picolinic acid markedly increased it. It is not clear why the present findings differ with respect to picolinate but, interestingly, in non-inverted porcine gut sacs picolinate reduced $\mathrm{Zn}$ uptake (Hill et al. 1987). Thus it is possible that although a given ligand may impair $\mathrm{Zn}$ uptake at the brushborder membrane, it may still permit overall absorption either by maintaining ingested $\mathrm{Zn}$ in solution or by acting at another site, such as the basolateral membrane. For example, citrate in vivo reduces ${ }^{65} \mathrm{Zn}$ binding to the gut wall but increases its transfer into the carcass (Jackson et al. 1981).

\section{Phytate}

The present findings support the well-established inhibitory effect of phytate on $\mathrm{Zn}$ absorption (Fairweather-Tait, 1988) and confirm that this occurs intraluminally. The lowest phytate: $\mathrm{Zn}$ molar ratio used in these studies was $50: 1$, at which point marked inhibition of $\mathrm{Zn}$ uptake occurred; but ratios as low as 6:1 can impair absorption (Lonnerdal et al. 1988). The close agreement between the in vitro studies reported here and extensive in vivo studies provides some validation of the brush-border-membrane vesicles model. Unlike citrate and picolinate, which may reduce $\mathrm{Zn}$ uptake by brush-bordermembrane vesicles by the formation of complexes that prevent $\mathrm{Zn}$ binding to its membrane receptor, phytate reduces absorption by the formation of poorly soluble complexes (Kratzer \& Vohra, 1986).

\section{Histidine}

Histidine: $\mathrm{Zn}$ molar ratios of $1: 1$ and $4: 1$ had no effect on $\mathrm{Zn}$ uptake. Histidine is generally reported to enhance $\mathrm{Zn}$ absorption at both low and high ligand: $\mathrm{Zn}$ ratios (Seal \& Heaton, 1983; Wapnir et al. 1983). Although the difference may be concentration related, Scholmerich et al. (1987) found a $\mathrm{Zn}$ : histidine ratio of only $1: 2$ to enhance absorption in comparison with zinc sulphate in man. However, in their study the rate of absorption was unchanged, and so histidine may maintain $\mathrm{Zn}$ in solution under conditions where it might precipitate or bind to ligands of low bioavailability, and not have a direct effect on membrane $\mathrm{Zn}$ transport.

\section{Glucose}

The lack of a direct effect of glucose on Zn uptake was expected. Although monomeric glucose stimulates mineral absorption (Steinhardt \& Adibi, 1984), it is probable that rather than acting as a ligand, the absorbable carbohydrate has a non-specific effect in vivo arising, for example, from altered gastric emptying (Griessen et al. 1989). The present findings support this hypothesis. The slight negative effect of Polycose may have been a result of increased extravesicular osmolarity leading to reduced intravesicular volume. Polycose consists of chains of $\alpha(1 \rightarrow 4)$ glucose of variable length, and is hydrolysed at the brush-border membrane to glucose (Jones et al. 1983). It is a constituent of enteral nutrition products and enhances the absorption of $\mathrm{Zn}$, calcium and magnesium in vivo (Bei et al. 1986), possibly in a manner analogous to glucose.

Finally, these findings confirm that brush-border-membrane vesicles are a useful model for the investigation of lumen interactions between nutrients and trace metals. Although the results are difficult to extrapolate to the complex situation in vivo when many 
competing ligands are present in the intestinal lumen, nevertheless this model provides insight on mechanisms and sites of interaction previously observed in the intact animal.

The authors are grateful for the continuing support of the Special Trustees of St Thomas' Hospital. They also wish to thank Abbott Laboratories for the gift of Polycose.

\section{REFERENCES}

Albert, A. (1953). Quantitative studies of the avidity of naturally occurring substances for trace metals. Biochemical Journal 54, 646-654.

Bei, L., Wood, R. J. \& Rosenberg, I. H. (1986). Glucose polymer increases jejunal calcium, magnesium, and zinc absorption in humans. American Journal of Clinical Nutrition 44, 244-247.

Bensadoun, A. \& Weinstein, D. (1976). Assay of proteins in the presence of interfering materials. Analytical Biochemistry 70, 241-250.

Black, A. E., Wiles, S. J. \& Paul, A. A. (1986). The nutrient intakes of pregnant and lactating mothers of good socio-economic status in Cambridge, UK: some implications for recommended daily allowances of minor nutrients. British Journal of Nutrition 56, 5972.

Blakeborough, P. \& Salter, D. N. (1987). The intestinal transport of zinc studied using brush border membrane vesicles from the piglet. British Journal of Nutrition 57, 45-55.

Booth, A. G. \& Kenny, A. J. (1974). A rapid method for the preparation of microvilli from rabbit kidney. Biochemical Journal 142, 575-581.

Clarke, R. M. \& Hardy, R. N. (1971). Histological changes in the small intestine of the young pig and their relation to macromolecular uptake. Journal of Anatomy 108, 63-77.

Cousins, R. J. \& Smith, K. T. (1980). Zinc-binding properties of bovine and human milk in vitro: influence of changes in zinc content. American Journal of Clinical Nutrition 33, 1083-1087.

Dodds, W. J. (1982). The pig model for biomedical research. Federation Proceedings 41, 247-248.

Duncan, J. R. \& Hurley, L. S. (1978). Intestinal absorption of zinc: a role for a zinc-binding ligand in milk. American Journal of Physiology 235, E556-E559.

Evans, G. W. \& Johnson, P. E. (1980). Characterization and quantitation of a zinc-binding ligand in human milk. Pediatric Research 14, 876-880.

Fairweather-Tait, S. J. (1988). Zinc in human nutrition. Nutrition Research Reviews 1, 23-37.

Fuller, N. J., Evans, P. H., Howlett, M. \& Bates, C. J. (1988). The effects of dietary folate and zinc on the outcome of pregnancy and early growth in rats. British Journal of Nutrition 59, 251-259.

Ghishan, F. K., Said, H. M., Wilson, P. C., Murrell, J. E. \& Greene, H. L. (1986). Intestinal transport of zinc and folic acid: a mutual inhibitory effect. American Journal of Clinical Nutrition 43, 258-262.

Griessen, M., Speich, P. V., Infante, F., Bartholdi, P., Cochet, B., Donath, A., Courvoisier, B. \& Bonjaur, J.-Ph. (1989). Effect of absorbable and nonabsorbable sugars on intestinal calcium absorption in humans. Gastroenterology 96, 769-775.

Haase, W., Schafer, A., Murer, H. \& Kinne, R. (1978). Studies on the orientation of brush border membrane vesicles. Biochemical Journal 172, 57-62.

Hill, D. A., Peo, E. R. \& Lewis, A. J. (1987). Effect of zinc source and picolinic acid on ${ }^{65} \mathrm{Zn}$ uptake in an in vitro continuous-fiow perfusion system for pig and poultry intestinal segments. Journal of Nutrition 117, 1704-1707.

Hurley, L. S. \& Lonnerdal, B. (1981). Picolinic acid as a zinc-binding ligand in human milk : an unconvincing case. Pediatric Research 15, 166-167.

Hurley, L. S., Lonnerdal, B. \& Stanislowski, A. G. (1979). Zinc citrate, human milk and acrodermatitis enteropathica. Lancet i, 677-678.

Jackson, M. J., Jones, D. A. \& Edwards, R. H. T. (1981). Zinc absorption in the rat. British Journal of Nutrition 46, 15-27.

Jones, B. J. M., Brown, B. E., Loran, L. S., Edgerton, D., Kennedy, J. F., Stead, J. A. \& Silk, D. B. A. (1983). Glucose absorption from starch hydrolysates in the human jejunum. Gut 24, 1152-1160.

Keating, J. N., Wada, L., Stokstad, E. L. R. \& King, J. C. (1987). Folic acid: effect on zinc absorption in humans and in the rat. American Journal of Clinical Nutrition 46, 835-839.

Kratzer, F. H. \& Vohra, P. (1986). Chelates in Nutrition. Boca Raton, Florida: CRC Press.

Krebs, N. F., Hambidge, K. M., Hagerman, R. J., Peirce, P. L., Johnson, K. M., English, J. L., Miller, L. L. \& Fennessey, P. V. (1988). The effects of pharmacologic doses of folate on zinc absorption and zinc status. American Journal of Clinical Nutrition 47, 783.

Lonnerdal, B., Bell, J. G., Hendrickx, A. G., Burns, R. A. \& Keen, C. L. (1988). Effect of phytate removal on zinc absorption from soy formula. American Journal of Clinical Nutrition 48, 1301-1306.

McMaster, D., Ewing, A. S., Erwin, C., McBriar, D. L. \& Love A. H. G. (1985). The influence of dietary vitamins on zinc uptake from the lumen of the perfused rat gut. Nutrition Research Suppl. 1, 267-270.

May, P. M., Smith, G. L. \& Williams, D. R. (1982). Computer calculations of zinc (II)-complex distribution in milk. Journal of Nutrition 112, 1990-1993. 
Meadows, N. J., Ruse, W., Smith, M. F., Day, J., Keeling, P. W. N., Scopes, J. W., Thompson, R. P. H. \& Bloxam, D. L. (1981). Zinc and small babies. Lancet ii, 1135-1137.

Menard, M. P. \& Cousins, R. J. (1983a). Zinc transport by brush border membrane vesicles from rat intestine. Journal of Nutrition 113, 1434-1442.

Menard, M. P. \& Cousins, R. J. (1983b). Effect of citrate, glutathione and picolinate on zinc transport by brush border membrane vesicles from rat intestine. Journal of Nutrition 113, 1653-1656.

Milne, D. B., Canfield, W. K., Mahalko, J. R. \& Sandstead, H. H. (1984). Effects of oral folic acid supplements on zinc, copper, and iron absorption and excretion. American Journal of Clinical Nutrition 39, 535-539.

Murer, H., Ammann, E., Biber, J. \& Hopfer, U. (1976). The surface membrane of the small intestinal epithelial cell. Biochimica et Biophysica Acta 433, 509-519.

Murer, H. \& Kinne, R. (1980). The use of isolated membrane vesicles to study epithelial transport processes. Journal of Membrane Biology 55, 81-95.

National Research Council (1980). Recommended Daily Allowances, 9th ed. Washington, DC: National Academy Press.

Prasad, A. S. (1984). Zinc deficiency in sickle cell disease. Progress in Clinical and Biological Research 165, 49-58.

Scholmerich, J., Freudemann, A., Kottgen, E., Wietholtz, H., Steiert, B., Lohle, E., Haussinger, D. \& Gerok, W (1987). Bioavailability of zine from zinc-histidine complexes. 1. Comparison with zinc sulphate in healthy men. American Joumal of Clinical Nutrition 45, 1480-1486.

Seal, C. J. \& Heaton, F. W. (1983). Chemical factors affecting the intestinal absorption of zinc in vitro and in vivo. British Journal of Nutrition 50, 317-324.

Simmer, K., Iles, C. A., James, C. \& Thompson, R. P. H. (1987). Are iron-folate supplements harmful? American Journal of Clinical Nutrition 45, 122-125.

Solomons, N. W. (1982). Biological availability of zinc in humans. American Journal of Clinical Nutrition 35, $1048-1075$.

Southon, S., Fairweather-Tait, S. J. \& Hazell, T. (1988). Trace element availability from the human diet. Proceedings of the Nutrition Society 47, 27-35.

Steinhardt, H. J. \& Adibi, S. A. (1984). Interactions between transport of zinc and other solutes in human intestine. American Journal of Physiology 247, G176-G182.

Wapnir, R. A., Khani, D. E., Bayne, M. A. \& Lifshitz, F. (1983). Absorption of zinc by the rat ileum: effects of histidine and other low-molecular-weight ligands. Journal of Nutrition 113, 1346-1354. 